\title{
Arabic language social and behavior change toolkit for family planning and reproductive health
}

Evidence Project

Follow this and additional works at: https://knowledgecommons.popcouncil.org/departments_sbsr-rh How does access to this work benefit you? Let us know!

\section{Recommended Citation}

Evidence Project. 2018. "Arabic language social and behavior change toolkit for family planning and reproductive health." Cairo: Population Council, The Evidence Project. 


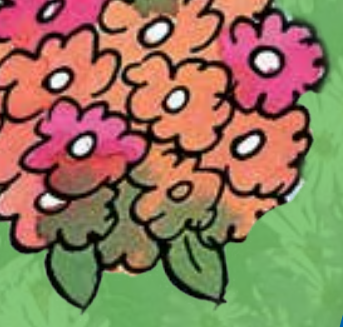

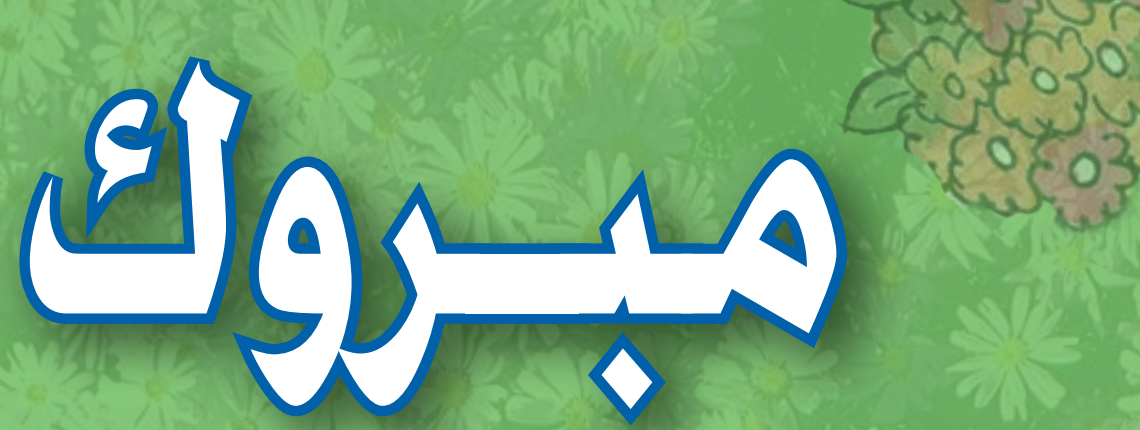
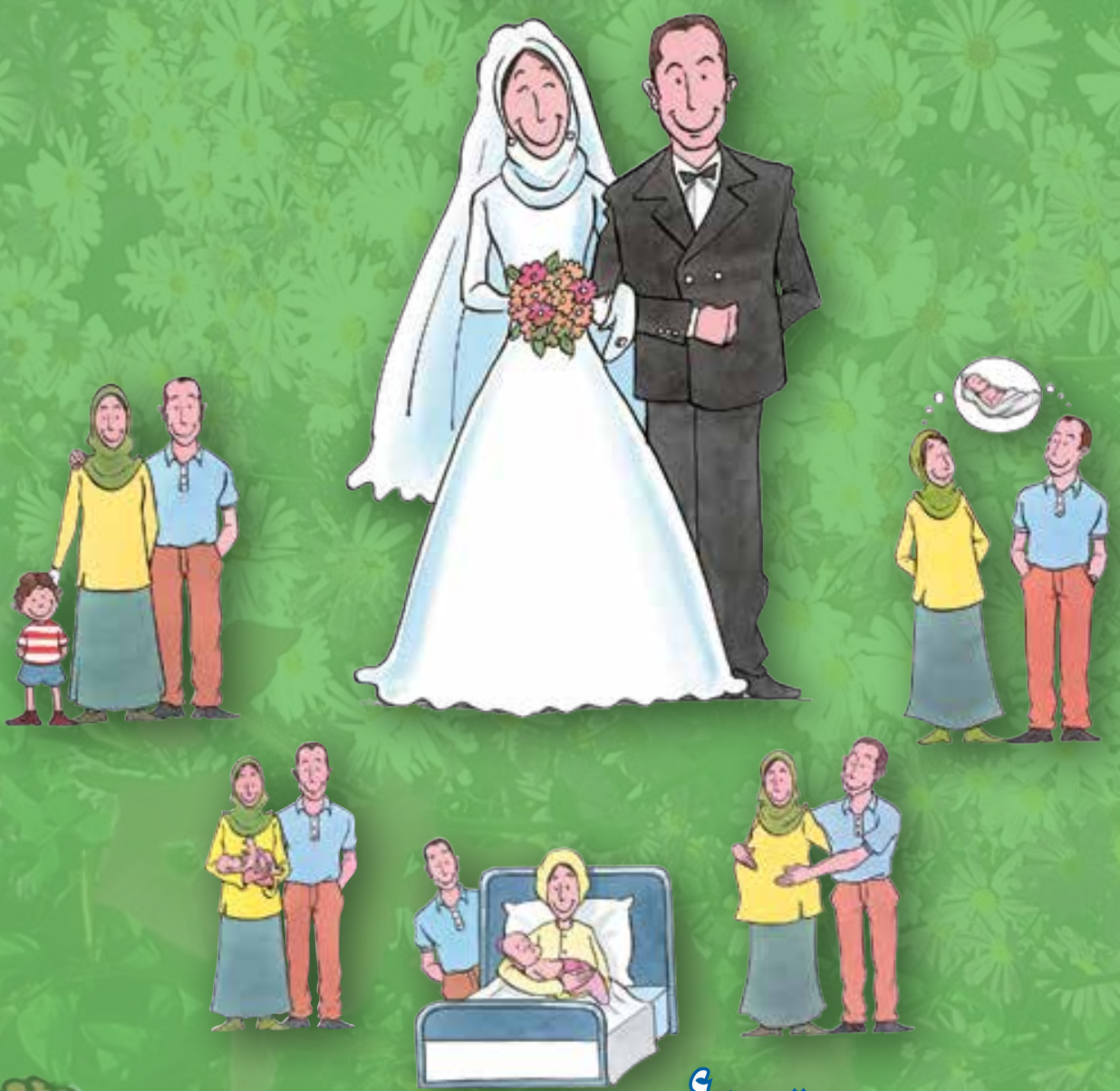

दिलि०ड०

त 100 a 


\section{إلى كل شاب وفتاة مقبلين

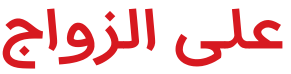

الزواج هو مرحلة مهمة في رحلة العمر وهو بداية تكوين

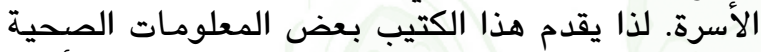

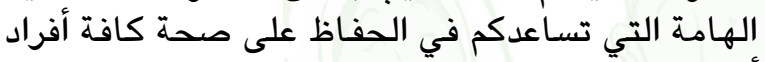
الأسرة.

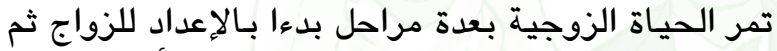

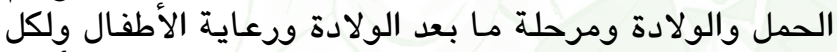

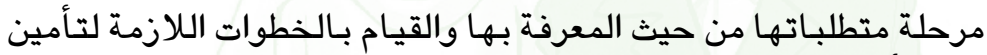
حالة صحية أفضل.

لذلك عليكم أن تعدوا نفسكم جيدا لهذا الحدث السعيد بـالذهـاب لأحد مراكز تقديم

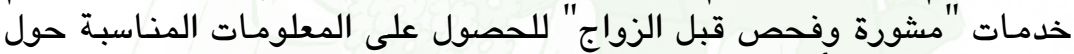

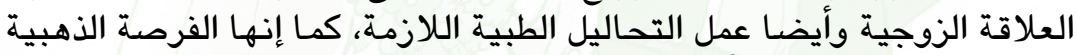

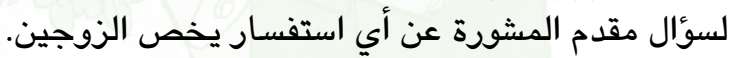

إذا كانت ظروفكم لا تسمح بـالحمل بعد الزواج مباشرة فمن الأفضل أن تخططوا

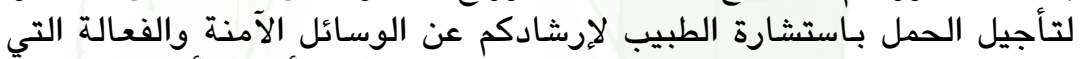

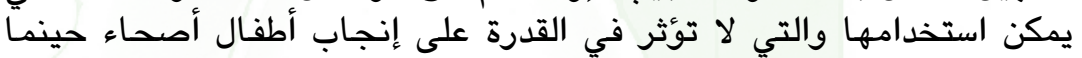
ترغبوا في ذلك.

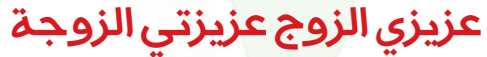

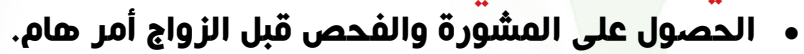

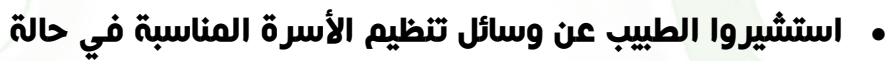
رغبتكما في تأجيل الحمل الأول 


\section{الاستعداد للحمل والإنجاب}

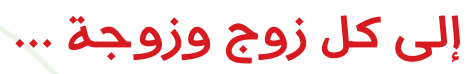

الحمل والإنجاب مسئولية مشتركة وعلى كل من الزوفي إنهاج والزوجة مناقشتها سويا. • قد يحدث الحمل بعد الزواج مباشرة أو بعد عدة شهور من الزواج.

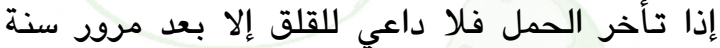

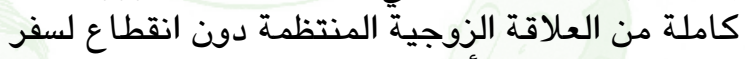

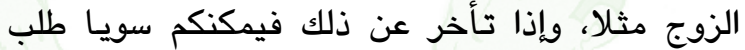
المشورة والكشف الطبي.

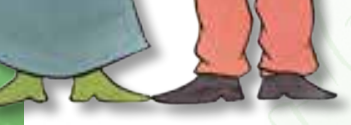

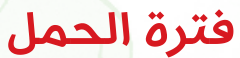
مبروك، فاليوم علمتم بالحمل وخلال عدة شهور سيأتي مولود جديد ينضم لأسرتكم السعيدة، ولكن ذلك يحتاج إلى بعض وخل الخطوات الهامة.

\section{فعليكي عزيزتي الزوجة ...}

الحفاظ على صحتك عزئي وصحة الزوحة الجنين من خلال اتباع الخطوات التالية: 1) متابعة الحمل: من المهم متابعة الحمل باستمرار مئ الطبيب المعالج وذلك الك الكالية

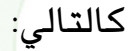
• مرة كل شهر خلال الـ آ أشهر الأولى من الحمل. • مرة كل أسبوعين خلال الشهرين السابع والثالمن الثرل. • • مرة كل أسبوع خلال الشهر التاسع.

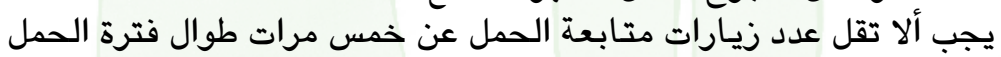

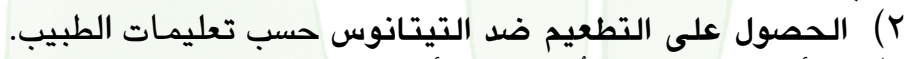

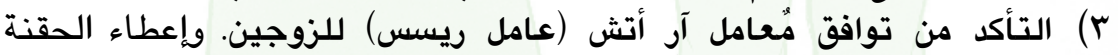

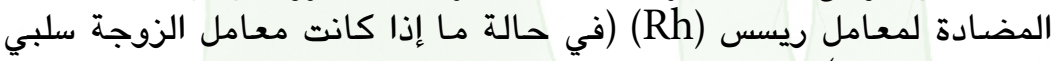
وزوجها إيجابي) ع) النظافة الشخصية: الاهتمام بالاستحمام اليومي والامتناع عن عمل دش إش

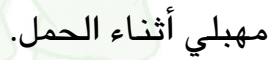




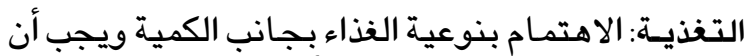

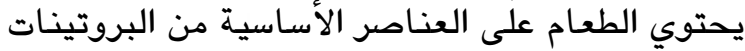

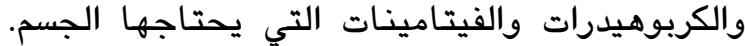

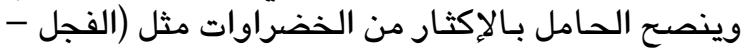

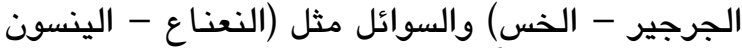

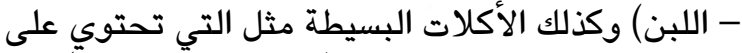
غذاء متكامل وصحي ومتنوع الألات (نشويات - بروتين).

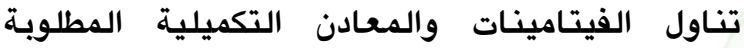
(خاصة الحديد وحمض الفوليكاتك).

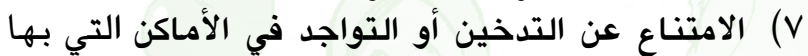
دخان. ^) عدم تناول أي أدوية بدون استشارة الطبيب. $(0$ 0 $(7$

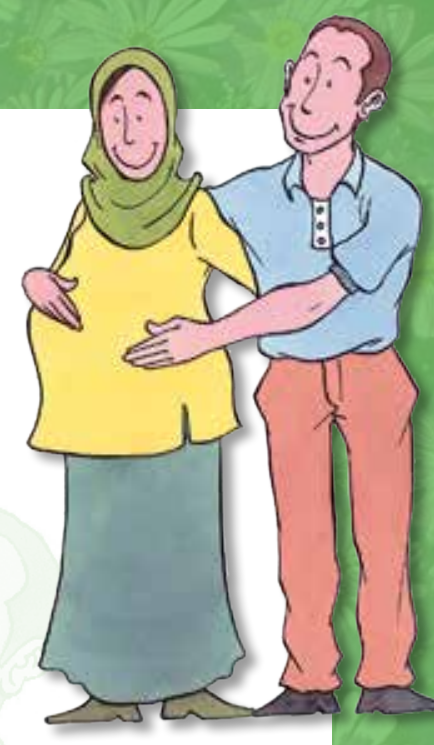

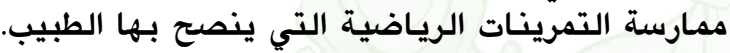

\section{أما أنت عزيزي الزوج ...}

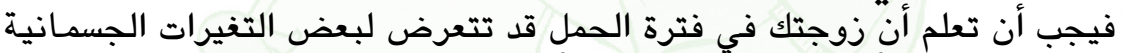

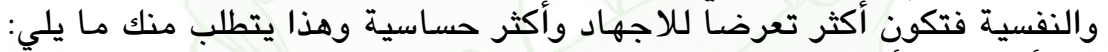

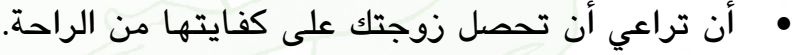

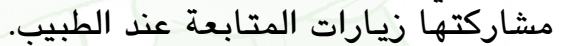

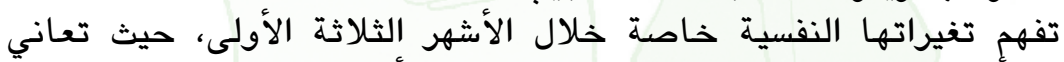

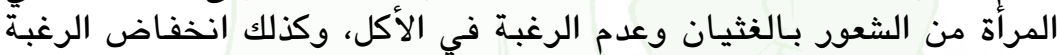
الجنسية لديها.

\section{الحمل والعلاقة الزوجية:}

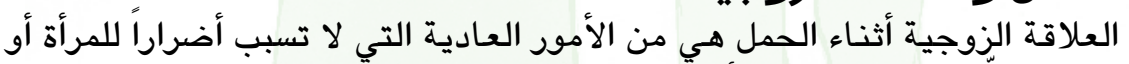

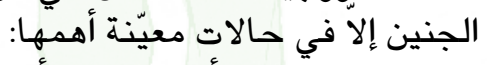

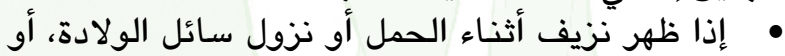

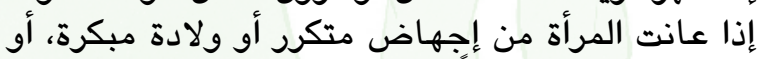

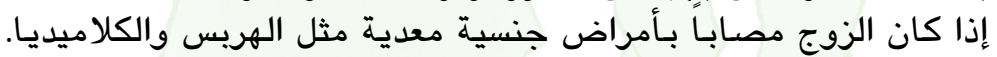




\section{عزيزتي الزوجة...}

لو كنتي تتعملين داخل مصنع فيجب عليكي مراعاة احتياطات السلامة التالية

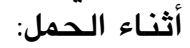
(التعرف على المواد الكيميائية المستخدمة في المصنع وتجنبها أو ارتداء

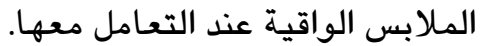

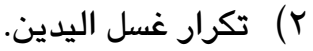

$$
\begin{aligned}
& \text { r) بنب الوقوف لفترات طويلة واستخدام كرسي مريح. } \\
& \text { ع) القيام بـالمشي لفترات قصيرة. }
\end{aligned}
$$

0) تجنب رفع الأحمال الثقيلة، والحرص على على ثني الركبتين والحفاظ على استقامة

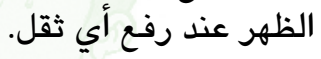
تجنب العمل لفترات طويلة في درجات فئ الحرارة المرتفعة كالأفران مع ضرورة شرب الكثير من السوائل.

علامات الخطر التي يجب التوجه فورًا إلى أقرب طبيب/مستشفى إنى عند حدوث أي منها هي:

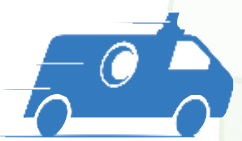

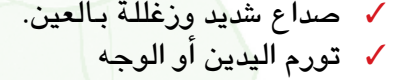

$$
\begin{aligned}
& \text { ل ل ارتفاع درجة الحرارة. }
\end{aligned}
$$

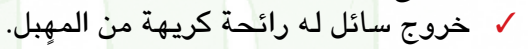

$$
\begin{aligned}
& \text { ل هزيف من المهبل حتى لو كان بسيطا. } \\
& \text { ل ألم بالبطن أو أسفل البطن. }
\end{aligned}
$$

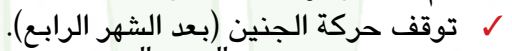

$$
\begin{aligned}
& \text { ل انفجار كيس المياه "القرن" قبل موعد الولادة. }
\end{aligned}
$$




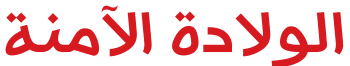

الولادة حدث هام تتذكره الأم مدي

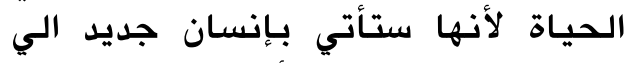

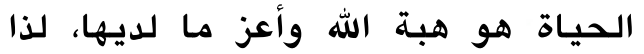

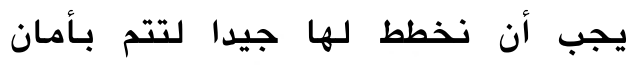
للأم وللجنين.

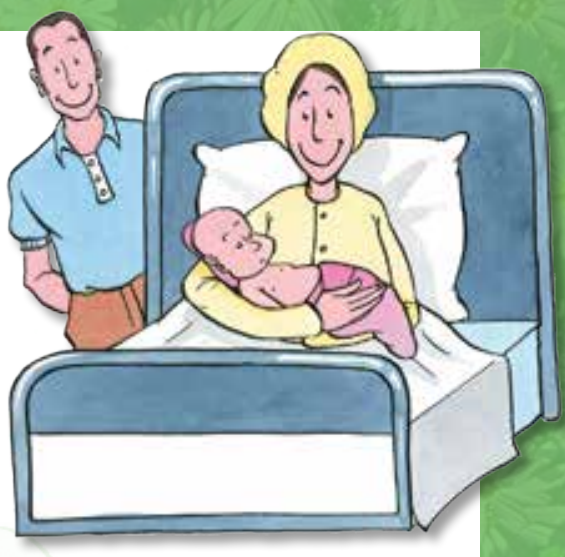

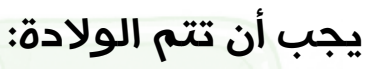

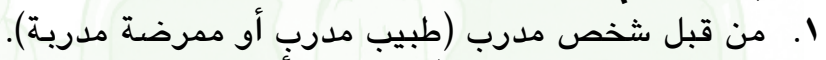
r. في مكان صحي مجهز (مع معرفة أقَرب مكان مدرفي للحصول مدربة) على الرعاية الطارئة

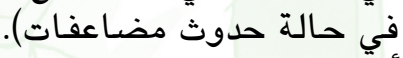

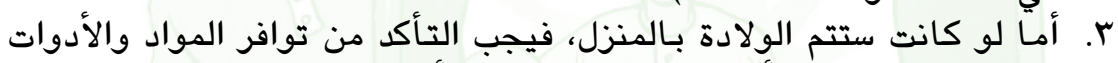

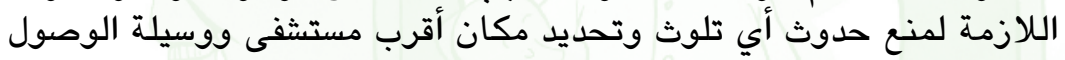
إليها حال الاحتياج لذلك. الكت

ملحوظة: يستمر الدخاض عادة ما بين ه إلى 1/ ساعة، ولكنه يتفاوت بين

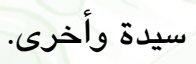

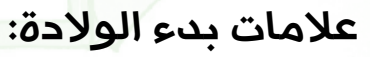

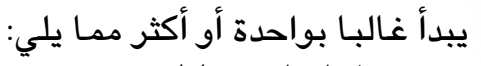

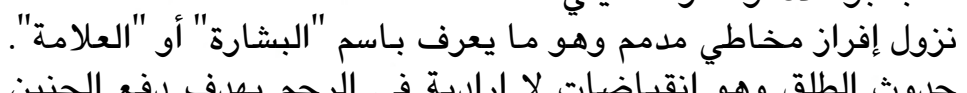

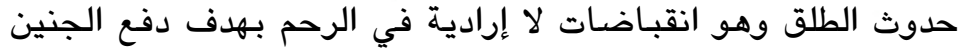

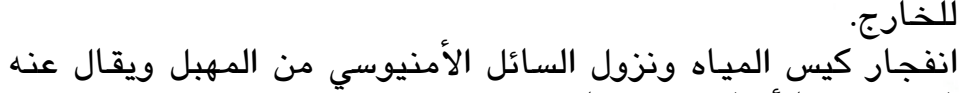

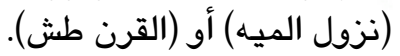




\section{مرحلة ما بعد الولادة}

\section{عزيزي الزوج، عزيزتي الزوجة ...}

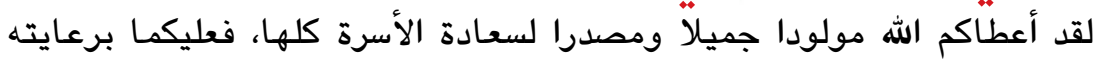

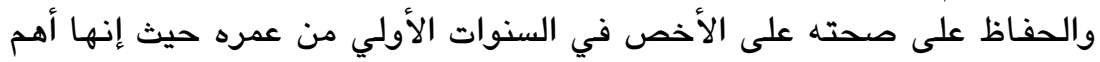

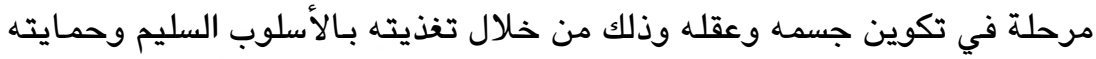

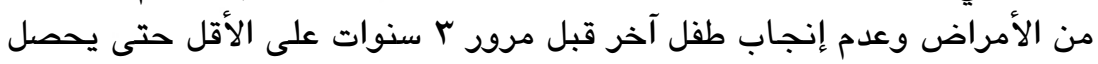
هذا المولود الجديد على القدر الكافي من رعايتكما.

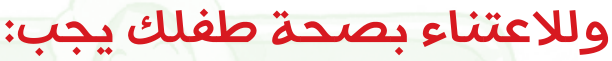

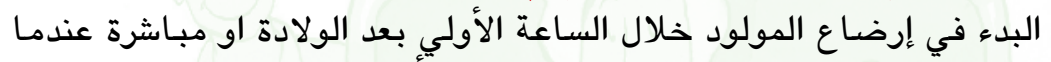

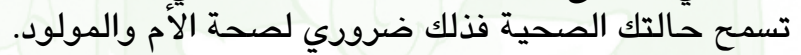

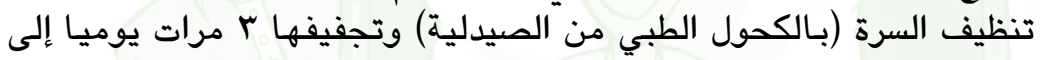

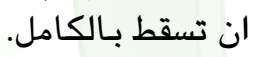
المحافظة على نظافة العينين للمولود وعدم وضع أي شيء بهما إلا القطرة

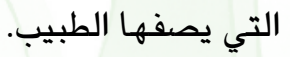
عرض المولود على الطبيب بين اليوم الثالث واليوم السابع بعد الولادة

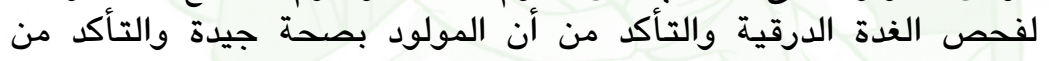

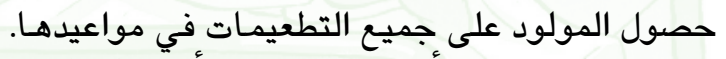

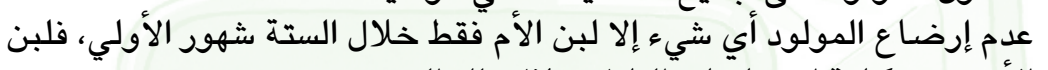

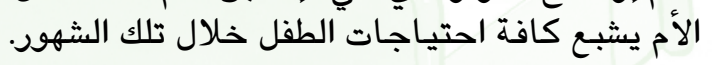

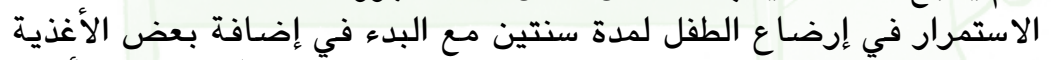

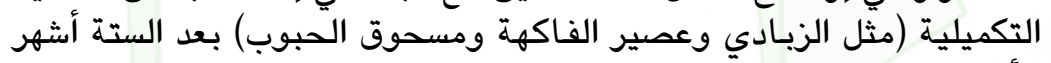

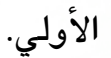
متأبعة وزن الطفل ونموه مـع الطبيب لحمايته من سوء التغذية التي قد تؤدي إلى آثار سيئة تنعكس على نموه الجسدي والعقلي. 
أما أنت عزيزتي الأم، فعليكي:

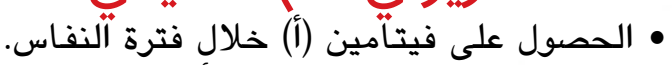

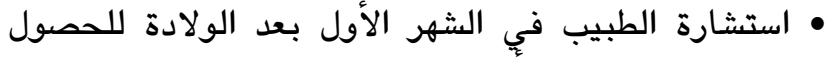

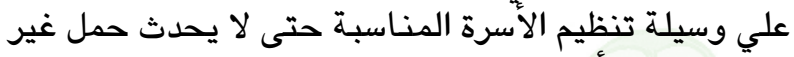
متوقع، حيث أن انقطاع الدورة الشهرية لا يعني الحماية ليحلية

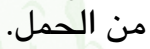

• مدارسة التمرينات الرياضية التي ينصح بها الطبيب

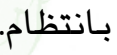
• الاهتمام بالتغذية الجيدة خصوصا السوائل لاستمرار

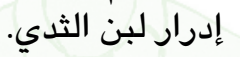

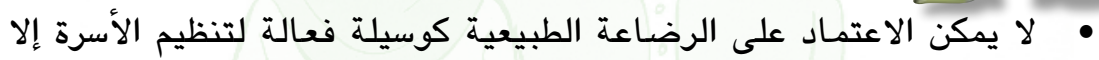
في حالة توافر الشروط الثلاثة التالية: - رضاعة مطلقة (تغذية الطفل من لبن الأم فقط في أثناء الليل والنهار ومن

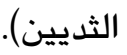

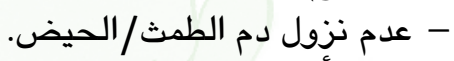
- خلال أول ستة شهور فقط بعد الحيضد الولادة.

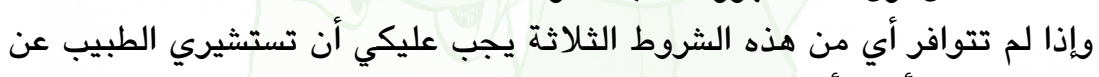
وسيلة تنظيم أسرة أخري مناسبة لها.

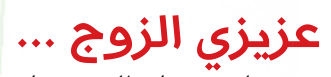

زوجتك تِّتاج الي مساعدتك في هذه المرحلة الصعبة فهي لاتستطيع القيام بكل الأمور

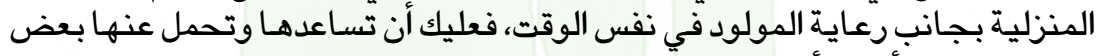

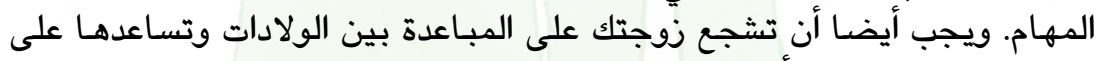

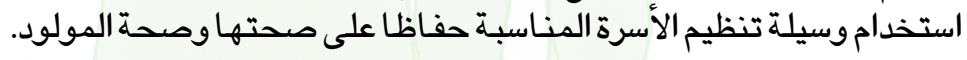

$$
\text { عزيزي الزوج عزيزتي الزوجة }
$$

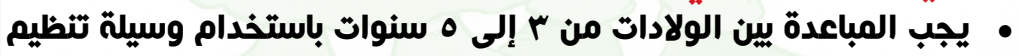

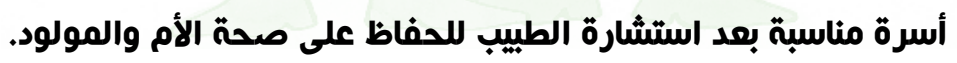
• استشيروا الطيبي خلال الشهر الأول بعد الولادة للحصول على على وسيلة تنظيم الأسرة المناسبة حتي لا يحدث حمل غير متوقع. 


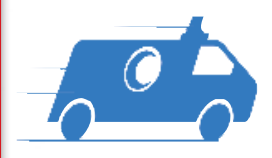

علامات الخطر في المولود والتي

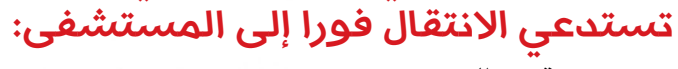
ل كعوية في التنفس.

/ ل لون جلد المولود غير طبيعي (أصفر أو شاحب أو أزرق)

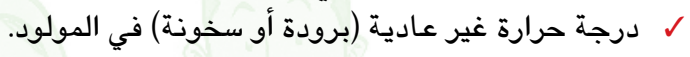
ل ك نوم المولود بصورة دائمة وعدم القدرة على إيقاظه لإرضاعهاءه. ل ل رفض المولود الرضاعة مرتين متتاليتين بعد الولادة. ل ال كروج دم أو صديد من السرة.

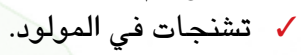

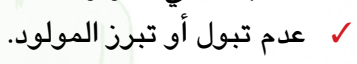

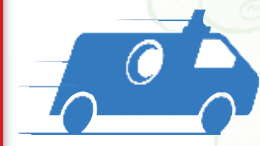

علامات الخطر للأم بعد الولادة والتي

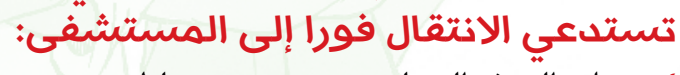

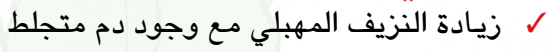

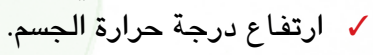
ل الم تشنجات. ل ك ألم شديد في منطقة البطن أو الحوض.

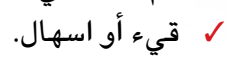
ل افرازات مهبلية مدممة أو لها رائحة كريهة.

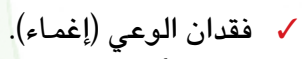
ل الم انتفاخ أو احمرار الثديين أو القدمين.

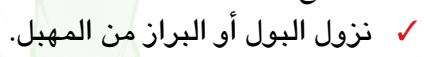

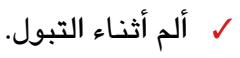
ل في حالة الولادة القيصرية: ألم و تورم و افرازات من جرح العملية. 


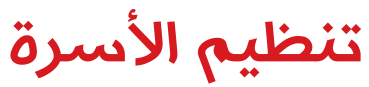

\section{عزيزي الزوج عزيزتي الزوجة ...}

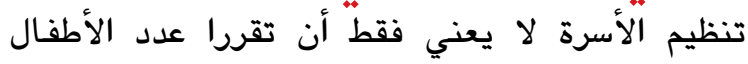

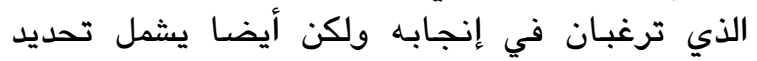

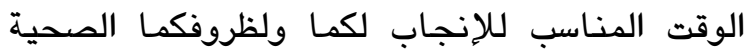

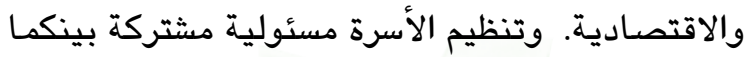

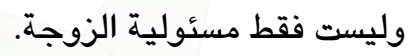

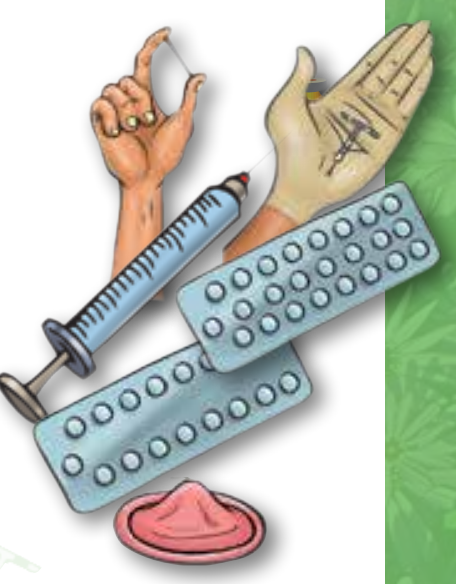

\section{تنظيم الأسرة له العديد من الفوائد} على الأسرة مثل: لأسرة

للأم:

يتيح للأم فرصة الحصول على الراحة واستعادة صحتها بعد عملية الحمل

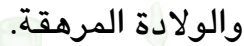
يقلل من مضاعفات الحمل والولادة كالأنيميا والإجهاض والولادة المبكرة. يقلل من حدوث الوفيات بين الأمهات. يُمِكن الأم من الاهتمام بدراستها أو عملها ومستقبلها.

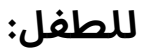

• يمكن الطفل من الحصول على الرضاعة الطبيعية لمدة كافية.

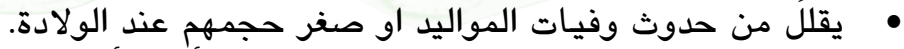
• • الحصول على الاهتمام والرعاية الكافية من الأم والأب.

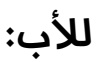

• لابتيح الفرصة للأب للتخطيط للعائلة ومستقبلها. يخفف من الأعباء المالية على الأب والأسرة كاملة. ويمُكنه من تحسين المستوي المعيشي والاقتصادي للأسرة. 


\section{وسائل تنظيم الأسرة: يوجد العديد من وسائل تنظيم الأسرة الحديثة منها:}

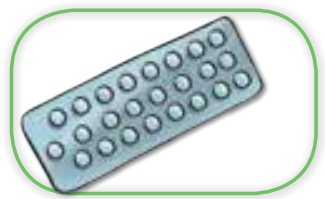

أقراص تنظيم الأسرة أحادية الهرمون

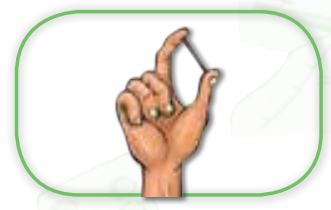

كبسولة تحت الجلد

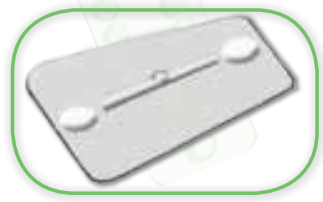

حبوب منع الحمل في الحالات الطارئة

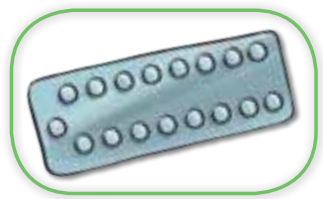

أقراص تنظيم الأسرة المركبة

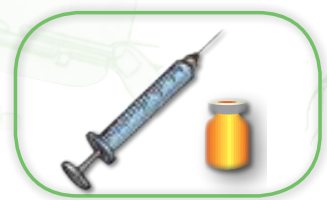

حقن تنظيم الأسرة أحادية الهرمون ( كل ب شهور) الادرة احسية

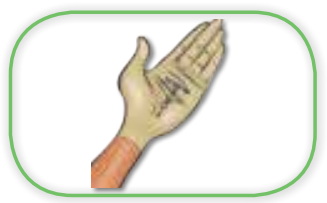

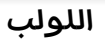

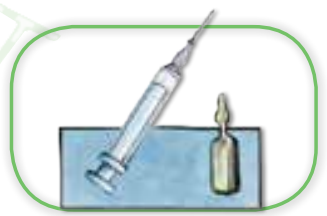

حقن تنظيم الأسرة المركبة (الشهرية)

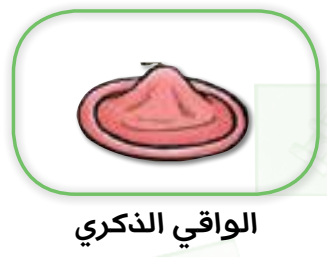

عزيزي الزوج وعزيزتي الزوجة:

اختيار وسيلة تنظيم الأسرّة هو قرارك أنت وزوجة وزتك دون دون إجبار على وسيلة معينة.

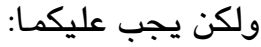
• • استشارة الطبيب عن وسائل تنظيم الأسرة الآمنة والفعالة والمناسبة لظروفكما. الالتزام بتعليمات الطبيب الخاصة باتل باستخدام الوسيلة. هعرفة كل المعلومات الخاصة بـالوسيلة وأعراضها الجانبية وكيفية التعامل معها. عدم الانقطاع عن استخدام الوسيلة أو استبدالها بوسيلة أخري إلا بعد استشارة الطبيب 


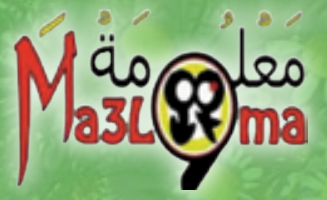

لمزيد من المهاومات عن الصسمة الإنجايية وتنطيم الأسرة

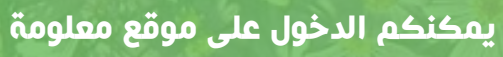

www.ma3looma.net

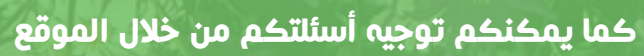

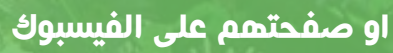

وسيصلك الإجابة خلال \& Y ساعة بسرية وخصوصية تامة

www.facebook.com/ma3looma.net 


\section{حقن تنظيم الأسبرة أحادية

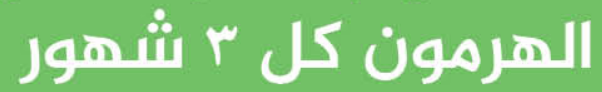

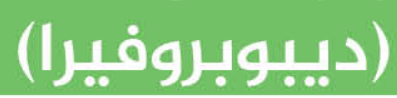

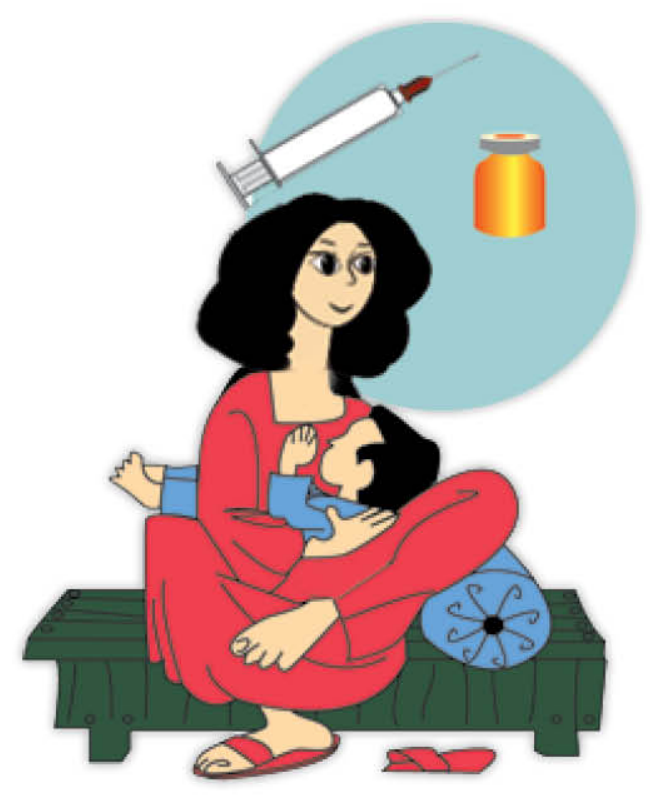

• • حقن تنظيم الأسرة آمنة وفعالة.

• يمكن استخدامها للسيدات المرضعات بعد الاسلا أسابيع من الولادة. • يمكن استخدامها للسيدات غير المرضعات بعد السادة الولادة و استخدامها بعد الإجهاض.

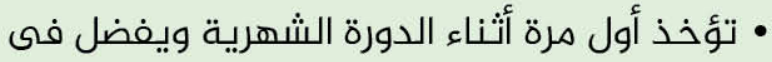
اليوم الأول من نزول الحيض.

\section{الكأُف الطبوى ضرورى قبل استخدام ألمام

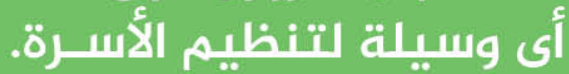




\section{• حقن تنظيم الأسرة تؤخذ في العضل كل ثلاثة

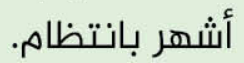 \\ • يتم قياس الضغط والوزن بصورة دورية. \\ • يجب أخذ الحقنة التالية فى الميعاد المحدد \\ لضمان فاعليتها.}

• قد تحدث بعض الأعراض الجانبية البسيطة فى

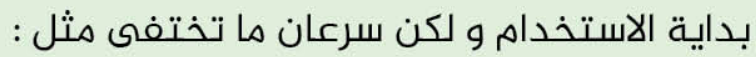

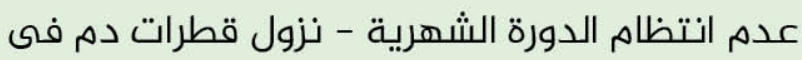
غير أوقات الحيض- انقطاع مؤقت للحيض.

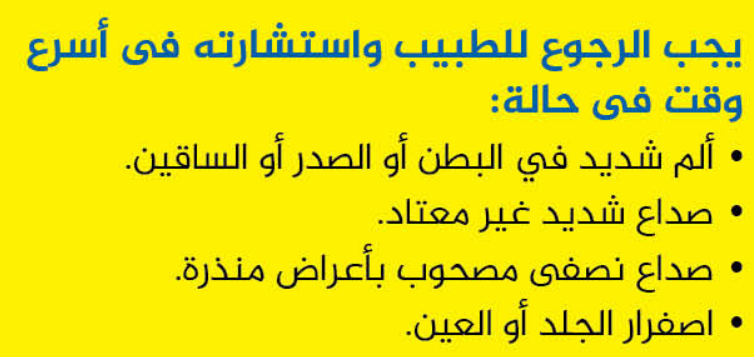

\section{(C) 0 \\ P 9}

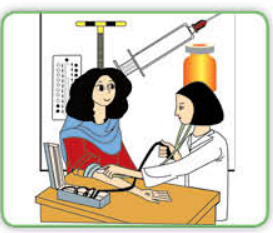

\section{لا تتوقفي عن استعمال الوسيلة

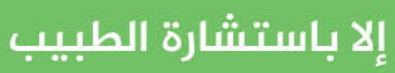

USAID Evidence 


\section{أقراص تنظيم الأسرة المركبة}

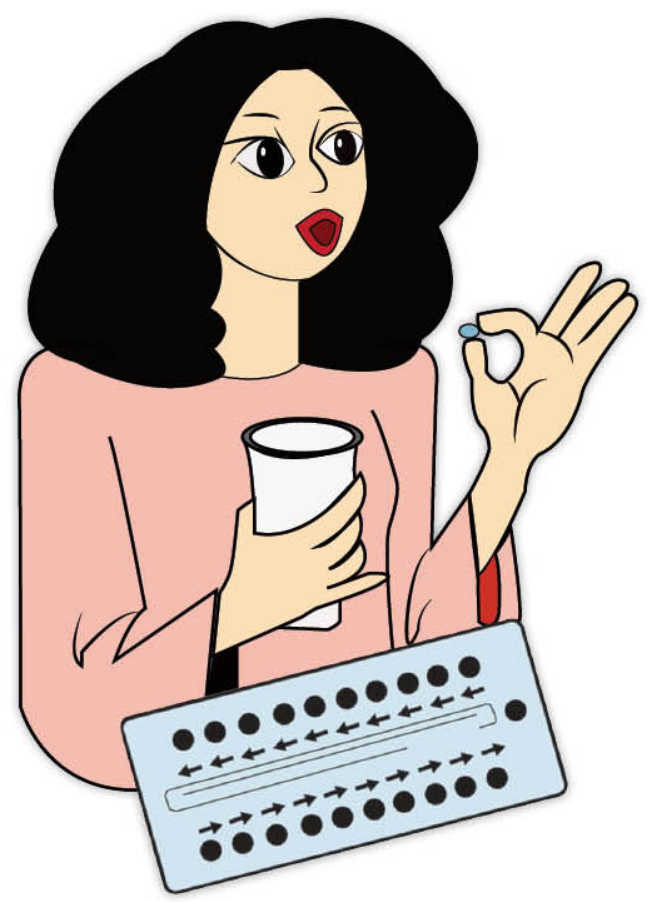

• حبوب تنظيم الأسرة آمنة وفعالة ولا تؤثر علي صحة الأم. • في أول مرة تستعملي الحبوب خديها أول يوم في الدورة الشهرية. • تناولى قرصاً واحداً كل يوم لمدة اب يوماً حتى ينتهى الشريط، دع اتباع السهم خلف الشريط. (حسب نوع الأقراص المتواجدة فى الأسواق)

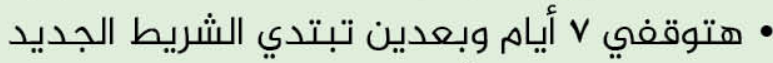
سواء الدورة نزلت أو مانزلتش.

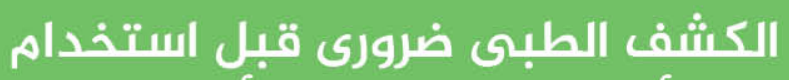

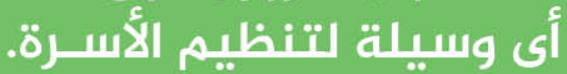


• يجب قياس الضغط بصورة دورية.

• إذا نسيتي قرص أو قرصين، خذي قرص أورة أول ما تفتكري والثاني في ميعاده.

• إذا نسيتي r أقراص، خذي قري مرص أول ما ما تفتكري

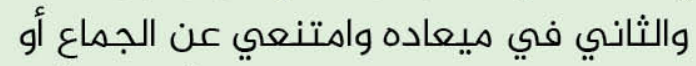
استخدمي الواقى الذكرى لمدة أسبوع وأستشيرى الطبيب فى اقرب وقت.

• فى حالة حدوث قهء أو اسهال أكثر من يومين يجب

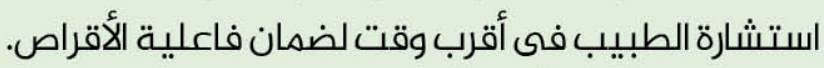
• قد تحدث بعض الأعراض الجانبية البسيطة فى أفى بداية الاستخدام و لكن سرعان ما تختفى مثل: غثيان- صداع بسيط- نزول قطرات دم فى غير

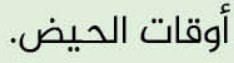

يجب الرجوع للطبيب واستشارته فى أسرع وقت في حالة: • • ألم شديد في البطن أو الصدر أو الساقين. • صداع شديد غير معتاد. • • صداع نصفى مصحوب بأعراض منذرة. • • • اصفرار الجلد أو العين. • • نسيان أكثر من r أقراص متتالية.
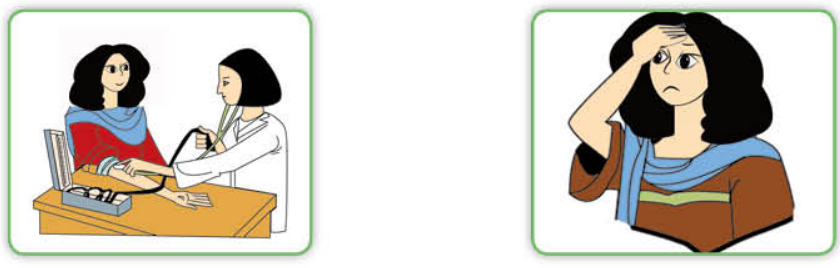

$$
\text { لا تتوقفي عن استعمال الوسيلة باستارة الطبيب }
$$




\section{الواقي الذكري}
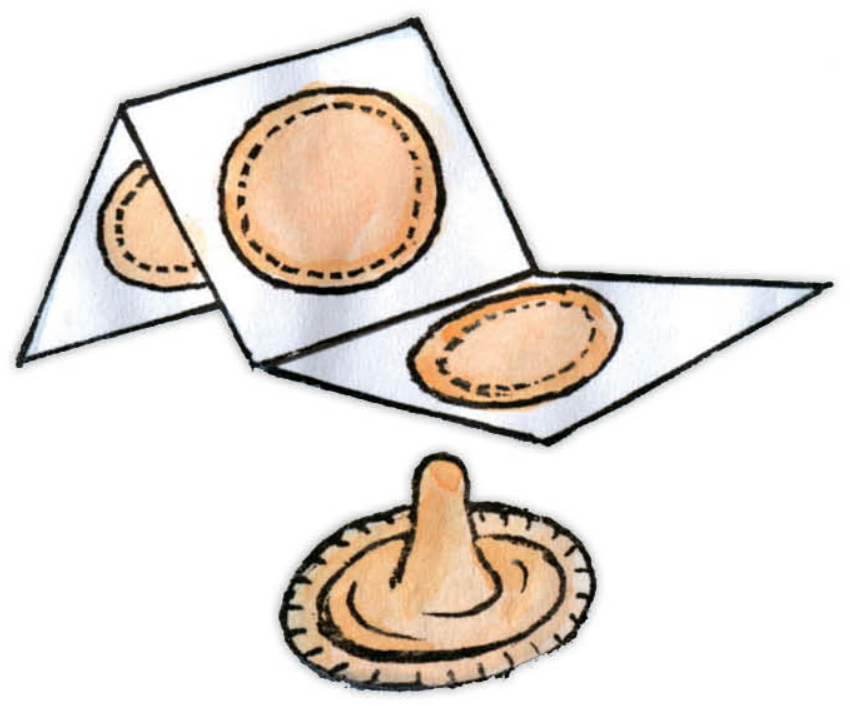

• الواقى الذكرى وسيلة آهنة للحماية من الحمل ومن الأمراض المنقولة جنسياً.

• وسيلة تساعد على مشاركة الزوج.

• يجب استشارة الطبيب لمعرفة الطريقة الصحيحة

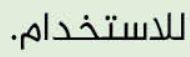

\section{الكشف الطبيى ضرورى قبل استخدام أى وسيلة لتنظيم الأســرة.}


• يناسب الأزواج في أي سن و مع من لا تستطيع زوجاتهم استخدام وسائل تنظيم أسرة أخرى.

• يحفظ في مكان جاف وبارد بعيداً عن الحرارة. • يستخدم مرة واحدة عند كل جماع وبعد الاستخدام يجب التخلص منه في سلة المهملات. • •ادراً ما يسبب حساسية لعدد قليل من الرجال

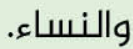

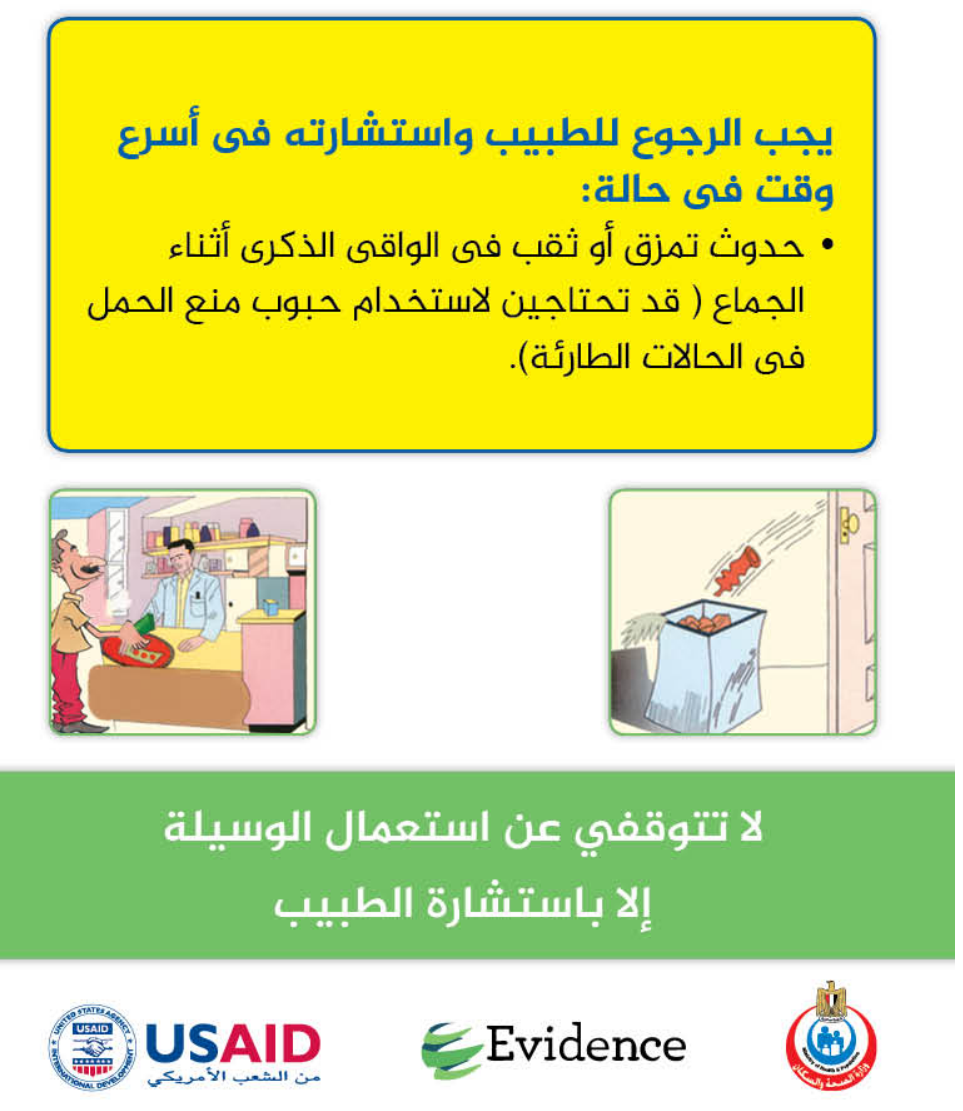




\section{حبوب منع الحمل فهى الصائة الحالات الطارئة الصنة فول}

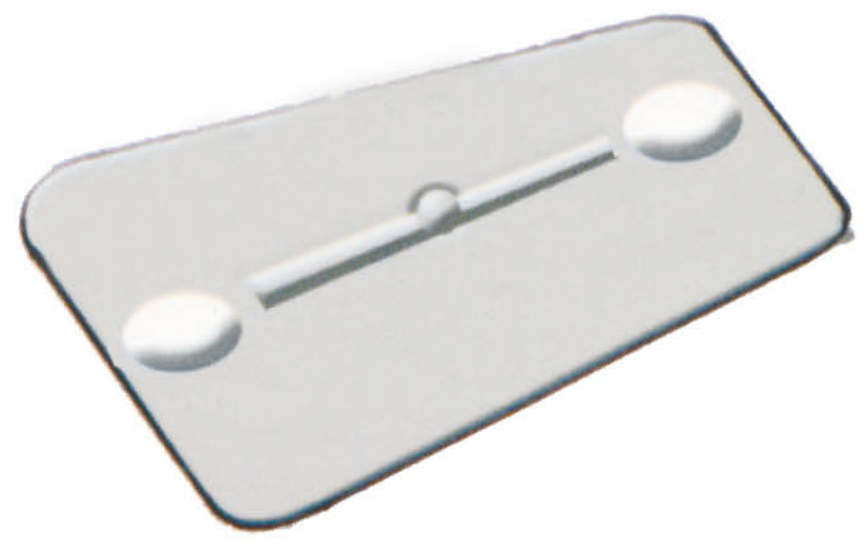

• وسيلة آمنة لمنع الحمل بعد الجماع غير المحمي.

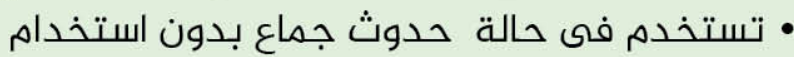
وسيلة أو مع استخدام خاطيى لوسيلة أو التأخر عن ميعاد الوسيلة. • كلما أسرعت السيدة في تناول الحبوب، كلما زادت فرصتها في الحماية من حدوث حمل. • يمكن أخذ الحبوب خلال ه أيام من الجماع غير فير

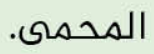

\section{الكشفف الطبى ضرورى قبل استخدام أى وسيلة لتنظيم الأســرة.}


• لا تستخدم هذه الحبوب كوسيلة بديلة عن وسائل تنظيم الأسرة.

• يؤخذ قرص بعد الجماع غير المحمى ثم قرص آخر بعد با ساعة و يمكن أخذ القرصين معاً فى نفس فرص الوقت و استشيرى الطبيب حسب نوع الحبوب.

• يجب البدء فى استخدام وسيلة فعالة لتنظيم

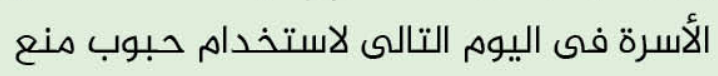
الحمل للحالات الطارئة.

يجب الرجوع للطبيب واستشارته فى أسرع

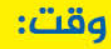
• •الاستخدام وسيلة تنظيم أسرة فعالة. • • إذا تأخر نزول الدورة الشهرية (لوجود إحتمال

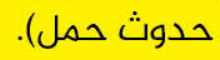
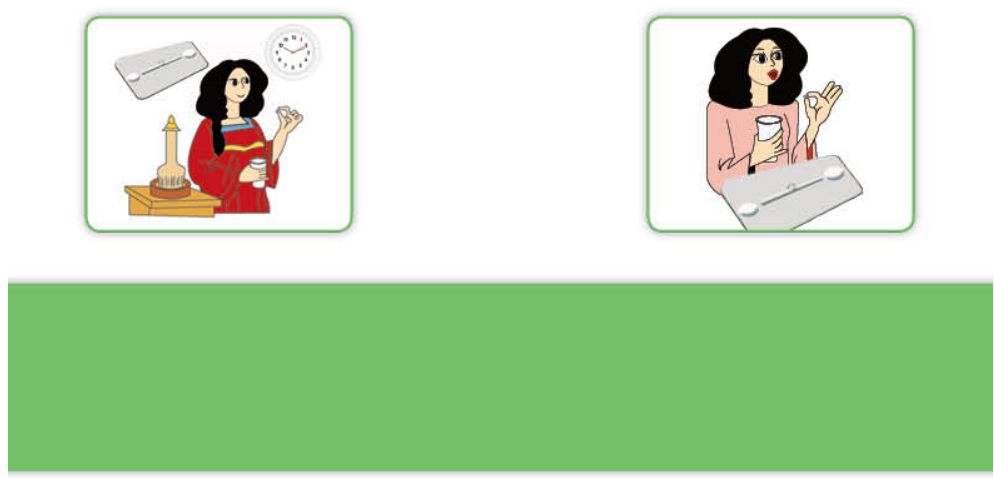

(:) USAID Evidence

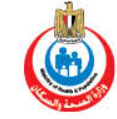




\section{اللولب النحاسسو}

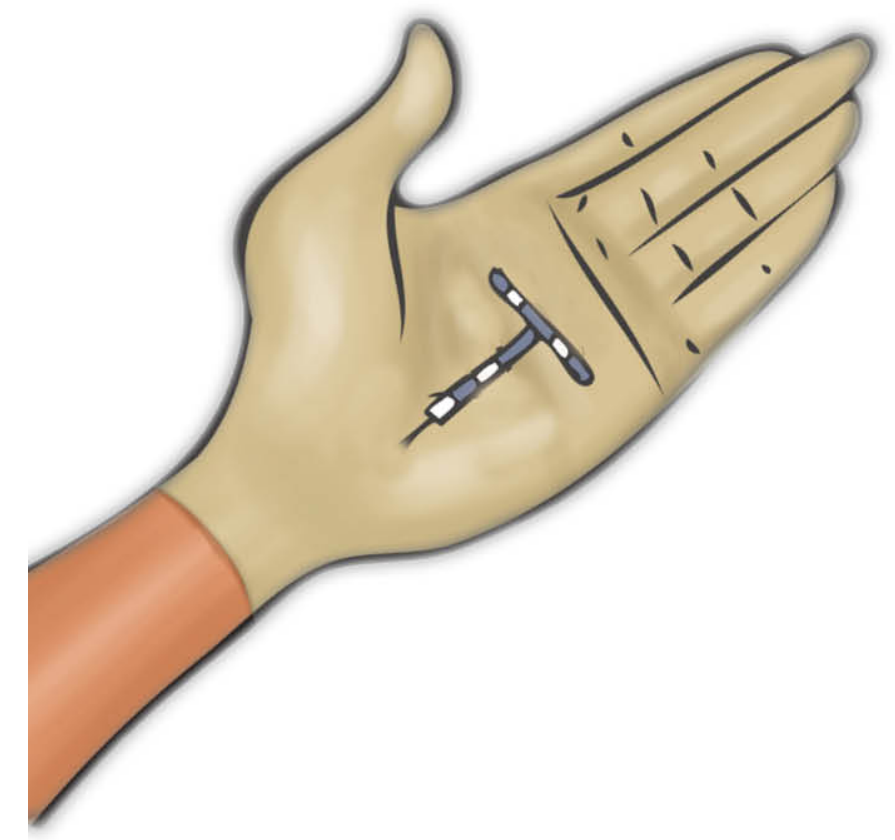

• وسيلة آمنة وفعالة. • يتم تركيبه داخل الرحم و يمكن إخراجه بسهولة بواسطة الطبيب فه حالة الرغبة فه الحمل.

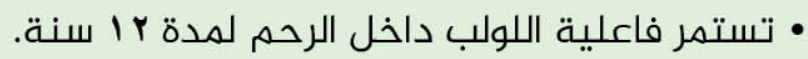

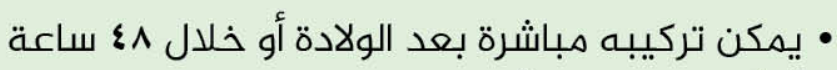
أو أثناء القيصرية أو بعد شهر من الولادة.

\section{الكشفف الطبى ضرورى قبل استخدام أى وسيلة لتنظيم ألأسلـرة.}


• يمكن تركيب اللولب بعد الإجهاض مباشرة بعد

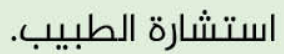
• يناسب السيدات أثناء الرضاعة الطبيعية.

• أول زيارة للمتابعة بعد أول دورة شهرية من تركيب اللولب أو بعد شهر ثم كشف دوري كل سنة.

• قد تحدث بعض الأعراض الجانبية مثل: زيادة بسيطة فى فترة الحيض مع زيادة فى كمية الدم، وحدوث بعض التقلصات الخفيفة.

يجب الرجوع للطبيب واستشارته فى أسرع وقت فى حالة:

نزيف شديد - ارتفاع درجة الحرارة مع ألم شديد أسفل البطن - عدم تحسس الخيط - تأخر الدورة الدمرة الشهرية.
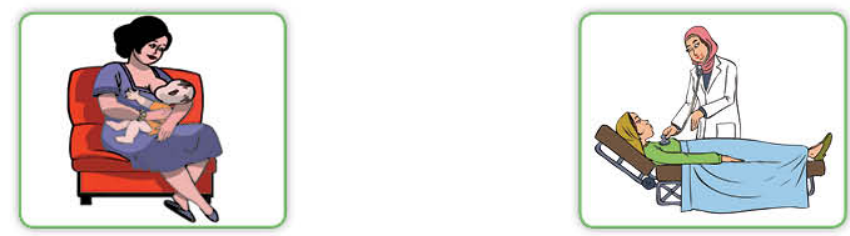

\section{لانتوفمفي عن استعمال الوسبلة إلا باستُارة الطبيب}

USAID Evidence

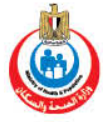




\section{حقن تنظيم الأسرة المركبة (الحقن الشهرية)}

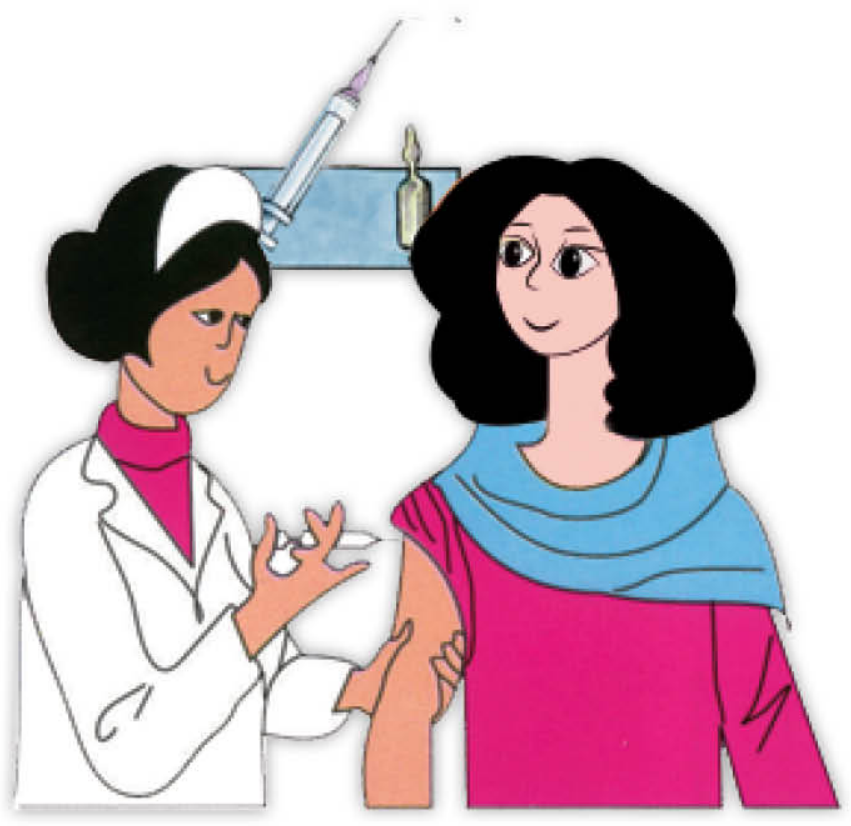

• حقن تنظيم الأسرة آمنة وفعالة ولا تؤثر علي

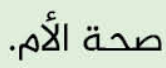

• تؤخذ أول مرة أثناء الدورة الشهرية ويفضل في اليوم الأول من نزول الحيض.

• ثم تؤخذ كل شهر بانتظام وبدون تأخير لضمان فاعلية عالية في منع الحمل.

\section{الكُشف الطبهى ضرورى قبل استخدام

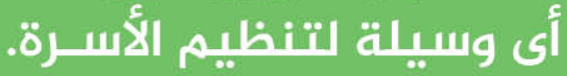


• يتم قياس الضغط و الوزن بصورة دورية.

• يمكن استخدامها للسيدات المرضعات بعد ج أشهر من الولادة .

• قد تحدث بعض الأعراض الجانبية البسيطة فى مانى بداية الاستخدام و لكن سرعان ما تختفى مثل: صداع خفيف - غثيان- نزول قطرات دم فى غير أوقات الحيض.

يجب الرجوع للطبيب واستشارته فى أسرع وقت فى حالة: • ألم شديد في البطن أو الصدر أو الساقين. • • صداع شديد غير معتاد.

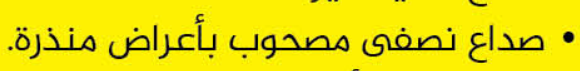
• اصفرار الجلد أو العين.
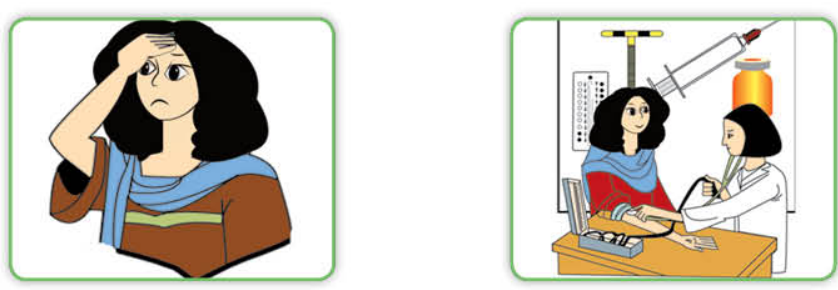

\section{لا تتوفمفي عن استعمال الوسبلة إلا باستُارة الطبيب}

USAID Evidence 


\section{أقراص تنظيم الألسرة أحادية الهرمون}
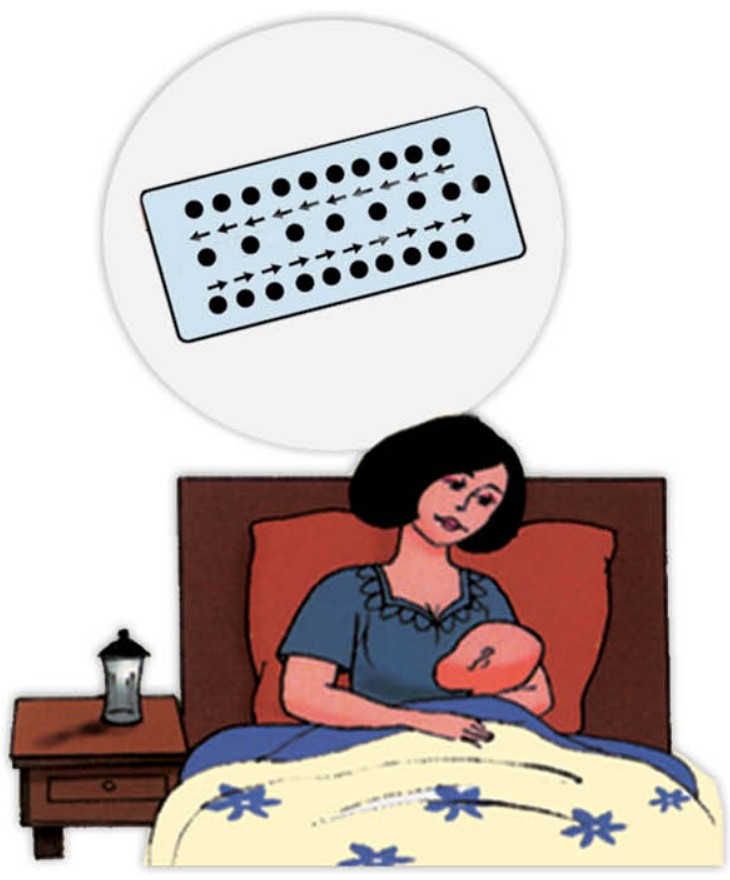

• حبوب تنظيم الأسرة آهنة وفعالة ولا تؤثر علي

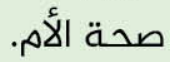
• وسيلة مناسبة مع الرضاعة.

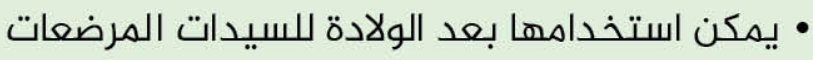
و غير المرضعات بعد استشارة الطبيب. • تناولى قرصاً يومياً بانتظام في ميعاد الثابت بداب بدون توقف وحتي أثناء الدورة الشهرية.

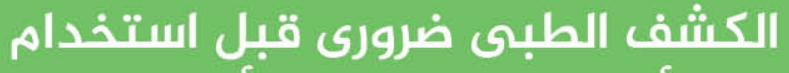

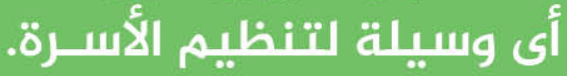


• بمجرد انتهاء الشريط أبدئسى شريط جديد فوراً فى اليوم التالى بدون توقف. • اذا نسيتي قرص أو اتأخرتي عن ميعاده أكثر من

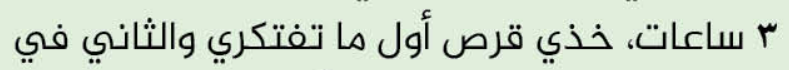

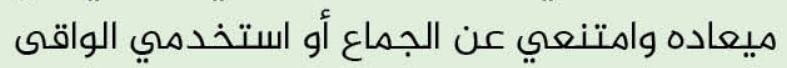

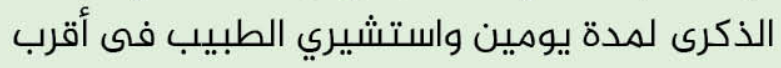

$$
\text { وقت. }
$$

• فى حالة حدوث قىء أو اسهال يجب استشارة

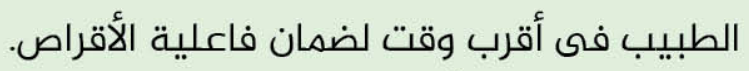

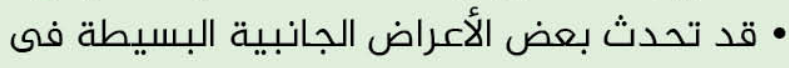

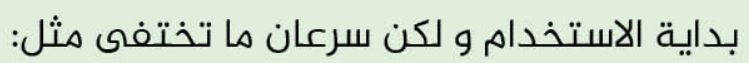
صداع بسيط- نزول قطرات دم فى غير أوقات الحيض- انقطاع مؤقت للحيض. نزول بـ

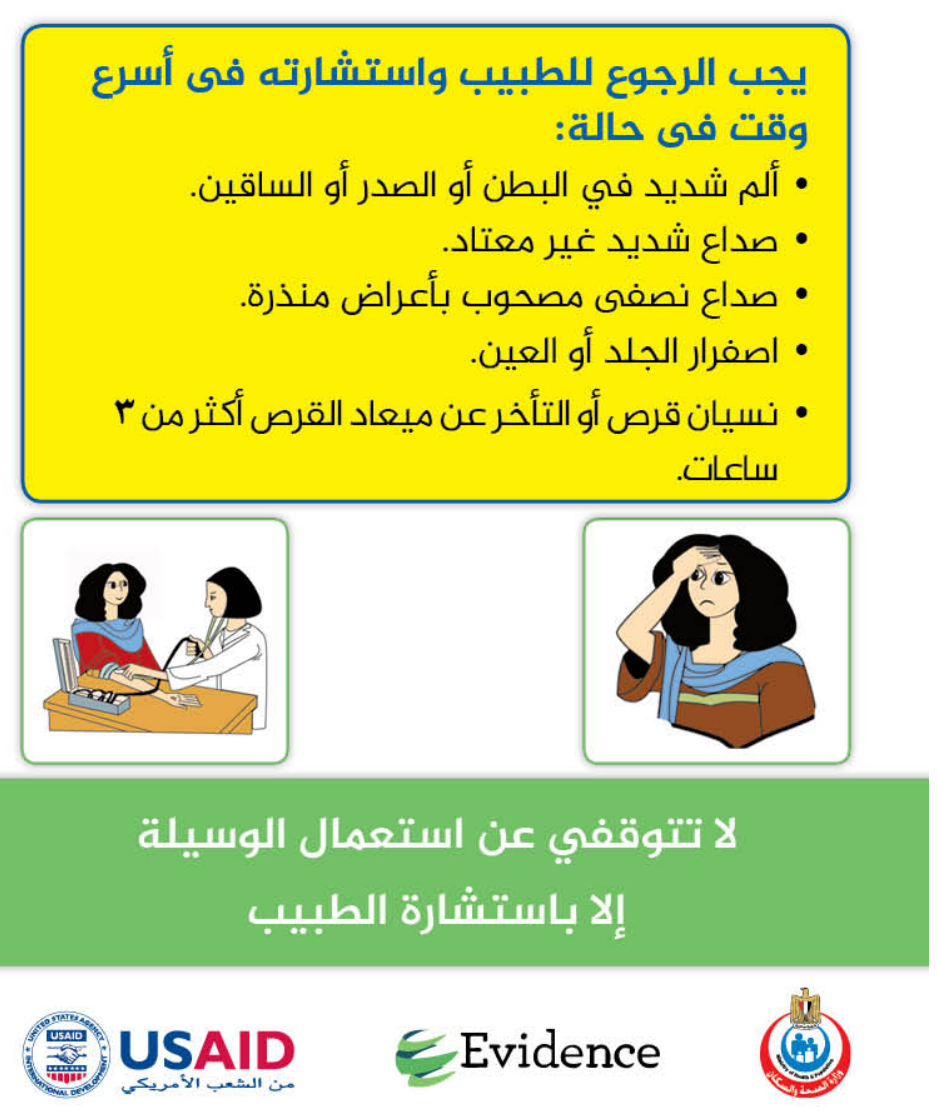




\section{كبسولة تحت الجلد

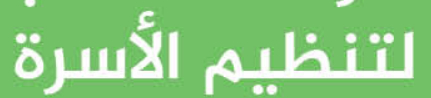

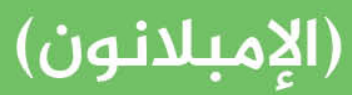
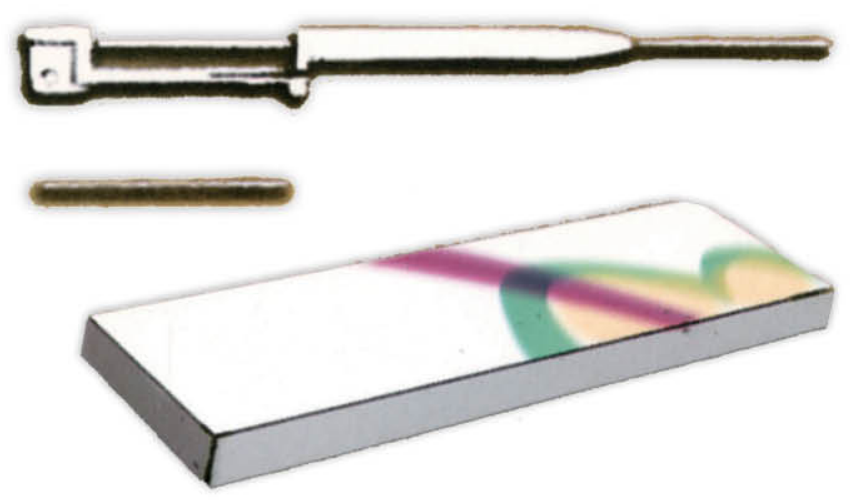

• كبسولة تنظيم الأسرة آمنة وفعالة ولا تؤثر علي

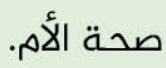

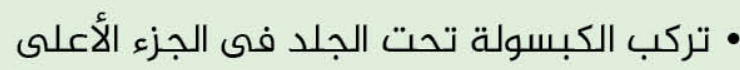
الداخلي من الذراع ولا تؤثر علي حركة الذراع.

• يتم تركيبها فى أى يوم من أيام الدورة الشهرية و يفضل فى اليوم الأول من نزول الحيض.

\section{الكأُف الطبوى ضرورى قبل استخدام أسبام

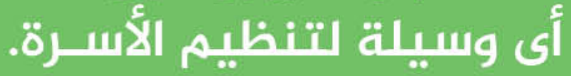


• يمكن استخدامها للسيدات المرضعات و للسيدات غير المرضعات بعد الولادة بعداستشارة الطبيب. • يمكن استخدامها بعد الإجهاض. • فعالة لمدة r سنوات.

• قد تحدث بعض الأعراض الجانبية البسيطة فى بداية الاستخدام و لكن سرعان ما تختفى مثل : عدم انتظام الدورة الشهرية - نزول قطرات دم فى ماله غير أوقات الحيض- انقطاع مؤقت للحيض. وقتب في الرجوع للطبيب واستشارته فى أسرع • • ألم شديد في في البطن أو الصدر أو الساقين.

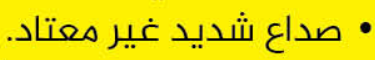
• • صداع نصفى مصحوب بأعراض منذرة. • • • اصفرار الجلد أو العين.
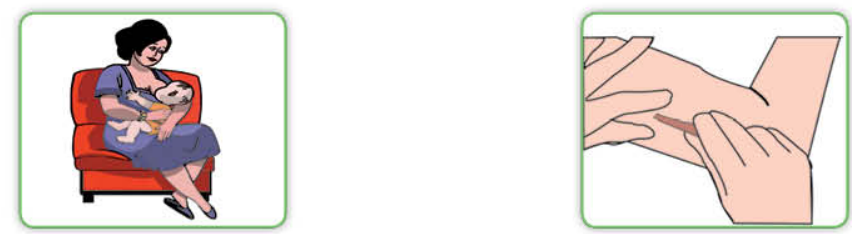

لا تتوقفي عن استعمال الوسيلة

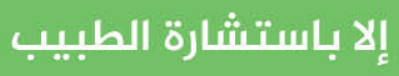

USAID Evidence 


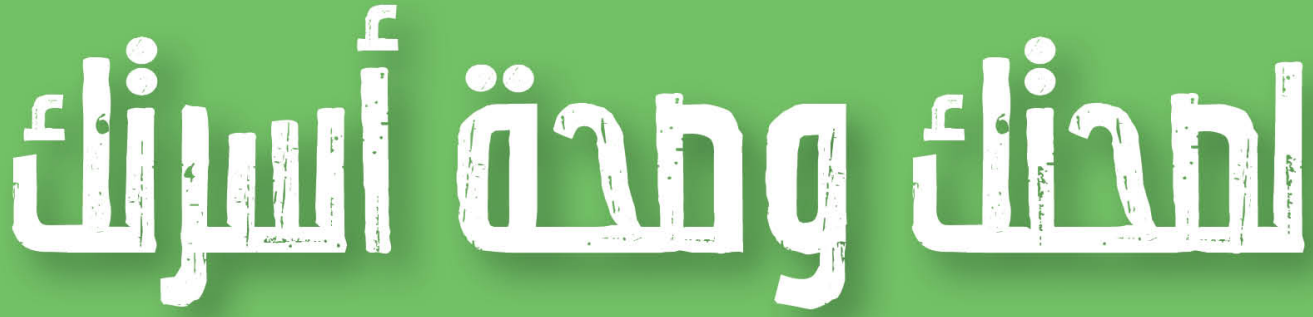

المباعدة بين الولادات من ب - 0 سانوات استشيري الطبيب عن وسيلة تنظيم الأسرة المناسبة المبل

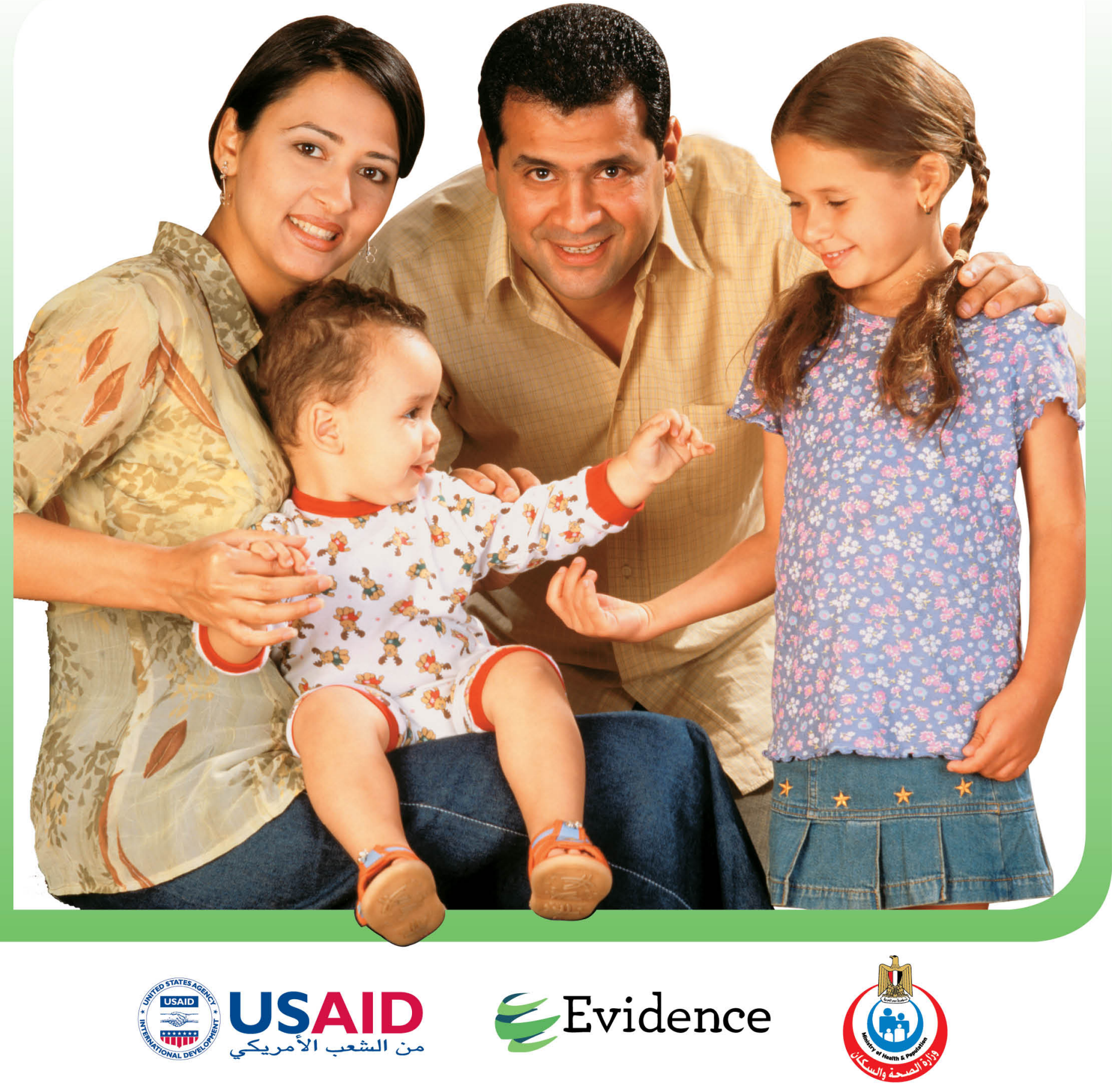




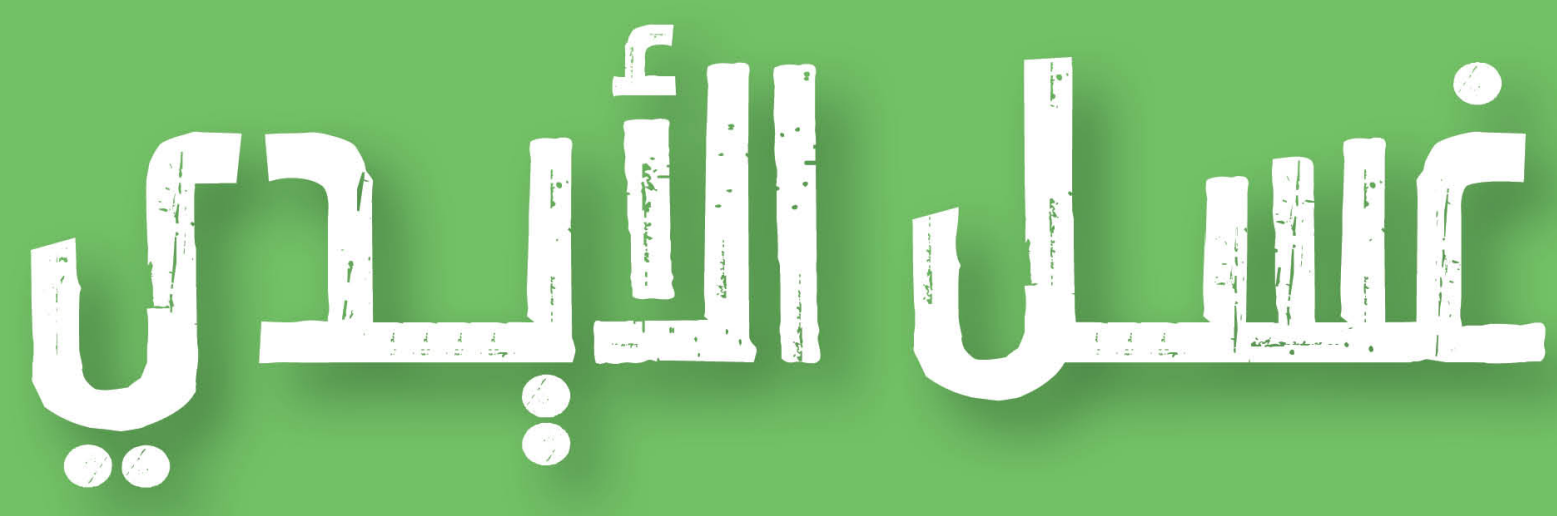

\section{الطرإِةقة السبإِمة لغسل الإدبان}

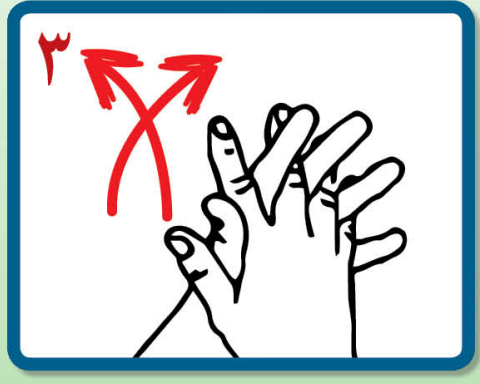

باطن اليد بباطن اليد الأخرى

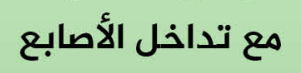

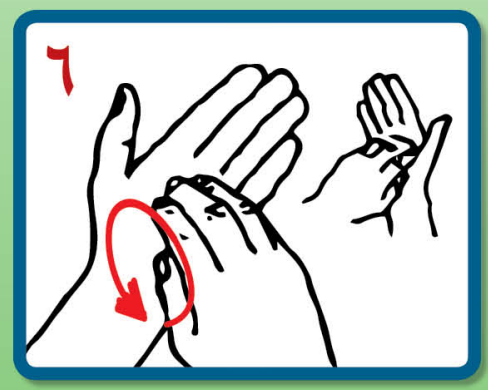

الدلك الدائرى للأمام والخلف بأصابع اليد اليمنى لباطن اليد اليسرى والعكس اليد ليمن لياطن

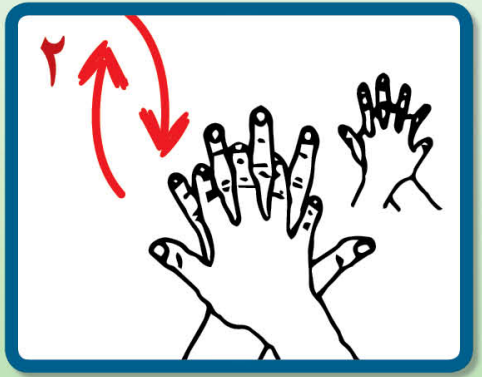

باطن اليد اليمنى على ظاهر اليد اليسرى هع تداخل الأصابع اليع اليدان والعكس نع نداخ

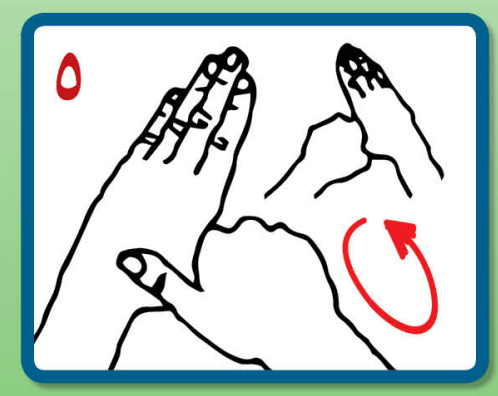

الدلك الدائرى للإبهام الأيسر ثم الأيمن لإليه

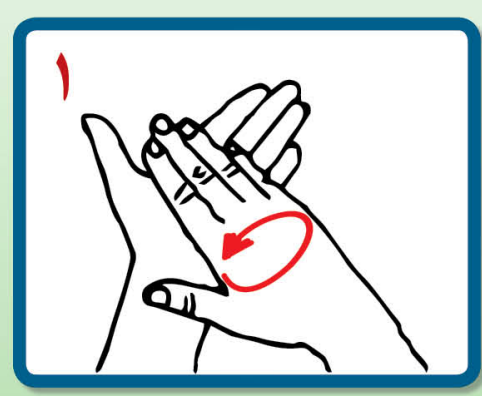

باطن اليد بباطن اليد الأخرى

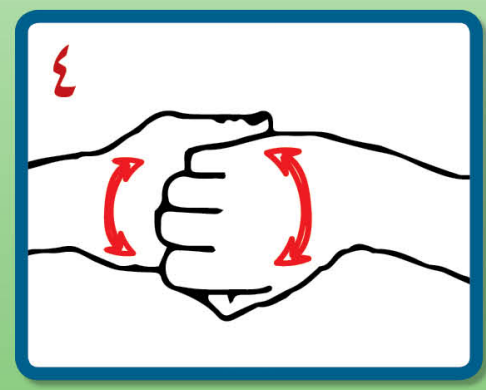

ظاهر الأصابع بباطن اليد الأخرى والأصابع مضمومة باطن 


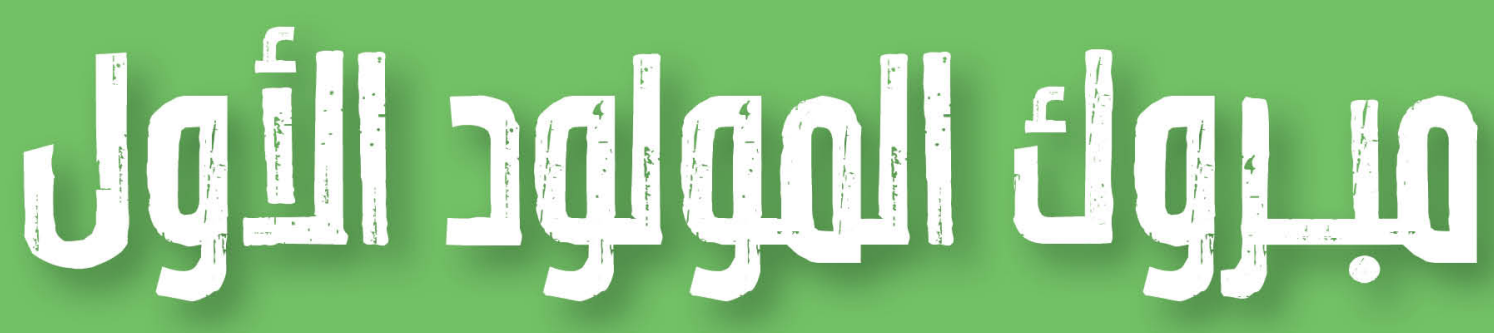

لصحتك وصحة المولود ... استُشيري الطبيب عن وسيلة تنظيم الأسرة الهناسبة بعد الولادة

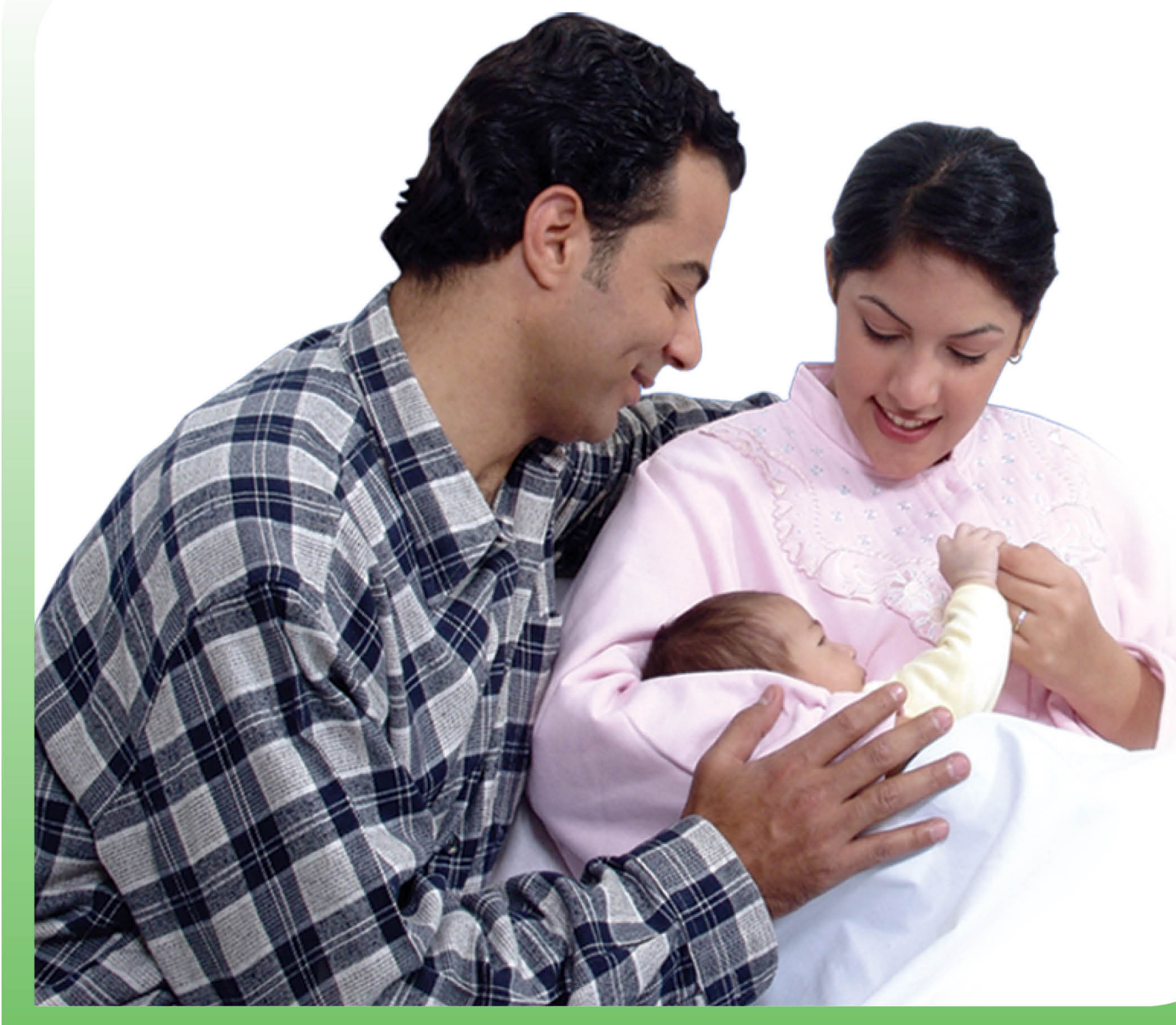

USAID Evidence (E) 